\title{
Age-friendly primary care health centers why are they necessary?
}

\begin{abstract}
Introduction: Health care humanization is a relevant line of work in recent times. Within it, the creation of age-friendly environments is relevant due to population aging. The aim is to review the characteristics of age-friendly environments in primary care and its possible impact on health.
\end{abstract}

Materials and methods: A review of the literature was made through a search in Medline Database. Studies about the characteristics health of age-friendly environments and health results derived from them were evaluated. Principal topics on the subject were extracted and summarized.

Results: Five studies were selected. Evidence on the subject is scarce. Some of the principal topics included physical barriers, communication issues, signaling and clinical procedures and protocols. Social factors might have greater influence on health rather than urban factor.

Conclusion: Physical barriers, clinical assistance, patient information, prevention and health promotion, social and community activities are the principal factors implicated in age-friendly Primary care Centers development. Further research must be made in order to describe the influence on physical and psychological health of age-friendly environments.

Keywords: physical barriers, environments, primary care, health, demographic change, community care, community activities, negative health events, psychological, physical therapies, health outcomes
Volume 2 Issue 4 - 2018

\author{
Acosta-Benito MA,' Rodríguez-Fernández $\mathrm{V}^{2}$ \\ Barrio-Cortes J, ${ }^{3}$ García-Pliego RA' \\ 'Specialist in Family and Community Medicine, Camilo José Cela \\ University, Spain \\ ${ }^{2}$ Work group on the elderly of the Madrid's Family and \\ Community Medicine Society's member, Spain \\ ${ }^{3}$ Work group on the elderly of the Spanish Family and \\ Community Medicine Society's member, Spain
}

Correspondence: Acosta-Benito MA, Specialist in Family and Community Medicine, Camilo José Cela University, Spain, Tel 661952093, Email maacostabenito@gmail.com

Received: June 07, 2018 | Published: July 16, 2018

\section{Introduction}

Aging has led to an important global demographic change and for the first time in history most of the population has a life expectancy equal to or greater than 60 years. It is well known that these changes are currently more noticeable in countries with medium or high incomes but the truth is that the pattern of aging in the population is much faster than in the past, constituting a global challenge. Every country faces important challenges to ensure their health and social system is prepared to deal with this demographic change. According to WHO's global report on aging and health, health systems should be better organized around the needs and preferences of older people to strengthen universal and integrated health care and people-centered health services. ${ }^{1,2}$ Several national and international institutions explain that Primary Care must be the fundamental pillar of health systems and therefore the adaptation of Primary Care to the elderly is essential to establish better strategies to maintain a better level of health in the person higher. In addition, according to Bárbara Star field, the best chronic strategy is Primary Care. ${ }^{3}$ Therefore, medical attention to the elderly should lead to increase quantity and quality of research in the context of family and community medicine..$^{2-4}$ Concepts such as "active aging" have been introduced as enriching factors in routine clinical practice, relating them to a lower incidence of negative health events, both physical and psychological. ${ }^{3-5}$

However, there is less evidence on the usefulness of modifying physical and functional cities environment to improve individual's health. ${ }^{4-6}$ Several barriers that hinder the adequate provision of information and care in the elderly have been identified, focusing on accessibility, received information, shared decision-making or opening hours in primary care centers, among others. ${ }^{7}$ There are several studies carried out around the creation of age-friendly urban models. It has been highlighted, for example, the importance of developing areas of activity for the elderly, where physical therapies and social resources are integrated. The use of new technologies must be enhanced in this population. ${ }^{8}$ However, the development of these lines of work in Primary care centers is very scarce. The objective of this review is to make a first assessment on the current status about the issue in relation to the presence of barriers for the elderly in Primary Care, and establish the main lines of action to get a center to acquire the necessary characteristics to consider it age-friendly.

\section{Methods}

A literature review on the studies published about the influence of the creation of age-friendly environments on health has been made, centered in primary care. Sources of information: a search has been carried out among the publications available in "Medline" database, using the terms "primary care" and "age-friendly". With the aim of not losing any relevant information, it was included related articles that appear as "suggestions" when consulting the ones obtained in the search, on a first level scale. Eligibility criteria: abstracts of the articles found were read, rejecting those that did not address the subject of interest, as well as those that were not related to primary health care and/or community care, or that did not express health results such as morbidity, mortality or similar. Selection of studies: all the articles that were not excluded for the reasons explained above were fully read, as well as those in which the reading of the abstract 
was not enough to decide on their incorporation into the review. Data analysis: the different studies were classified according to the topic related to the proposed measures to improve accessibility as well as the measured health outcomes.

\section{Results}

Selected studies: the search yielded a total of fifteen results. Ten

Table I Resume of the evidence in age-friendly health environments of them were discarded during the selection process. The reasons for rejecting these works were the absence of relationship with the subject studied, the absence in the study of health results and the appearance of guidelines or recommendations provided by international or national organizations. Figure 1 one includes a PRISMA schema that summarizes the search process. Characteristics of the studies: target, principal outcomes and main results of the selected studies are described in Table 1.

\section{Resume of the evidence in age-friendly health environments}

\begin{tabular}{|c|c|c|c|}
\hline Author & Target & Principal outcomes & Main results \\
\hline $\begin{array}{l}\text { Hawkersworth } \\
\text { et al. }\end{array}$ & $\begin{array}{l}\text { To explore a wide range of complex } \\
\text { environmental attributes that hypothetically } \\
\text { influence older adults' physical activity (PA) } \\
\text { in their neighborhood environments }\end{array}$ & Minutes per day spent in PA & $\begin{array}{l}\text { Social aspects have more influence } \\
\text { than physical barriers on the health of } \\
\text { the elderly }\end{array}$ \\
\hline Wand $D$ et al. & $\begin{array}{l}\text { To explore the contributions of neighboring } \\
\text { green space to cause-specific mortality }\end{array}$ & $\begin{array}{l}\text { Death from all-cause Respiratory system } \\
\text { disease Circulatory system disease. } \\
\text { Quantity of green space (\%) within a } 300 \\
\text { m radius }\end{array}$ & $\begin{array}{l}\text { Higher coverage of green space was } \\
\text { associated with reduced risks of all- } \\
\text { cause mortality, circulatory system- } \\
\text { caused mortality and stroke-caused } \\
\text { mortality }\end{array}$ \\
\hline Neville $S$ et al. ${ }^{10}$ & $\begin{array}{l}\text { To review actual evidence on the factors } \\
\text { related to building age-friendly rural } \\
\text { communities }\end{array}$ & $\begin{array}{l}\text { Theoretical perspectives- Geographic and } \\
\text { demographic characteristics. Partnerships. } \\
\text { Sustainability Future research agendas }\end{array}$ & $\begin{array}{l}\text { The available studies have severe } \\
\text { limitations. It seems that the most } \\
\text { influential factors are those related to } \\
\text { social problems }\end{array}$ \\
\hline $\begin{array}{l}\text { Alhamdan AA } \\
\text { et al. } .^{7}\end{array}$ & $\begin{array}{l}\text { To evaluate the health care services } \\
\text { provided for older adults by primary health } \\
\text { care centers and the ease of use of these } \\
\text { centers by older adults. }\end{array}$ & $\begin{array}{l}\text { Basic indicators of clinical services } \\
\text { offered. Factors indicative of the ease of } \\
\text { use of the centers by older adults based } \\
\text { upon the age-friendly PHCCs toolkit of } \\
\text { the WHO }\end{array}$ & $\begin{array}{l}\text { The clinical management of patients } \\
\text { reaches an acceptable level, however, } \\
\text { aspects related to information, physical } \\
\text { barriers and transportation must be } \\
\text { improved. }\end{array}$ \\
\hline Woo J et al. ${ }^{\prime \prime}$ & $\begin{array}{l}\text { To evaluate whether primary care services } \\
\text { are sufficiently oriented towards the older } \\
\text { population }\end{array}$ & $\begin{array}{l}\text { Education and training Community-based } \\
\text { health care management systems. Physical } \\
\text { environment }\end{array}$ & $\begin{array}{l}\text { Information Every domain must be } \\
\text { improved in order to get age-friendly } \\
\text { environments. }\end{array}$ \\
\hline
\end{tabular}

Articles identified trough bibliographic search and screened for relevance $(n=15)$

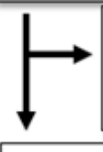

Excluded $(n=8)$

6 articles were not related to the topic

2 was related to actitudes and/or showed not health results.

Full text articles obtained for evaluation $(n=7)$

$\downarrow \begin{aligned} & \text { Excluded }(n=3) \\ & -1 \text { WHO guidelines } \\ & -1 \text { Experts opinion about age-friendly conceptual issues } \\ & -1 \text { General proposal of actions }\end{aligned}$

Studies elegible for inclusion $(n=5)$

$\longrightarrow$\begin{tabular}{l}
$-\begin{array}{l}3 \text { were connected to health results according to age-friendly } \\
\text { components } \\
2 \text { described principal barriers for the elderly }\end{array}$ \\
\hline
\end{tabular}

Figure I PRISMA diagram explaining the flow of the studies through the review.

\section{Principal topics}

Age-friendly environmental factors that may have some influence in health results: Several factors that may hinder health care of the elderly have been found related to physical difficulties in accessing to the health centers, in their structure and in the transmission of information. ${ }^{9-12}$ However, the available scientific evidence, which is very limited, does not allow generating reasonably firm conclusions. There are some elements that a health center that seeks to be agefriendly has to consider. These include accessibility from the patient's home to the health center, distance, means of transport, state of the roads and sidewalks and architectural barriers (stairs, ramps, curbs, etc.). ${ }^{9-12}$ In many cases, these elements do not depend directly on the primary health care center but in local administrations. The association found between improvement in health and decrease in mortality in the cities with the largest number of green areas ${ }^{10}$ is striking. Inside the health center, architectural barriers such as stairs have been described, but other physical elements may have a negative influence in the adaptation of the environment for the elderly: inadequate signage (in size, location and message), absence of handrails in the corridors, insufficient acoustic communication or non-adapted waiting areas, among others. ${ }^{10}$ 


\section{Aspects related to the handling of information}

Highlighted the importance $e^{10,11}$ of overcoming the difficulties related to communication so that the elderly patient can correctly understand the information, and consequently apply it to their functional situation. This can have a positive impact on health. Some authors proposed measures that include adaptation of the center's signage: adequate font size, acoustic signals and even Braille writing. It is important to emphasize the way in which professionals of the center inform the patient, and it is necessary to develop communication techniques that include make some questions to the patient to prove if he has understood all the relevant information.

\section{Clinical management of the elderly patient}

Only one of the studies included aspects related to the existence of specific health programs, such as early detection of cancer, management of chronic diseases, control of cardiovascular risk or other measures to promote health. ${ }^{7}$

\section{Community and social actions}

The actions related to population empowerment, creation of social support networks and other aspects related to the economic capacity of patients have been clearly relevant in the appearance of negative health events in the elderly, especially when they are related to a limitation in physical activity. ${ }^{6}$ The presence of community activities and health promotion have proved been useful in the context of policies to achieve age-friendly environments. The continuity between different levels of care has been shown as another determining factor in maintaining the health of the elderly. ${ }^{12}$

\section{Discussion}

None of the publications exactly followed the scheme proposed by the WHO for obtaining health centers that are friendly to the elderly, although it is true made a more faithful approach than the others. The document "Age-Friendly Primary Health Care Centers Toolkit" written by the WHO establishes firstly ${ }^{13}$ a series of recommendations oriented to prevention of disability and morbidity that include preventive services, clinical advice, counseling on toxic habits such as smoking, and advice on physical activity and nutrition. Within them, communication tools and tricks are exposed to solve the main barriers that we might find in the attention to elderly people in Primary Care centers. These recommendations can be supported by those developed by various scientific societies, taking into account the current evidence. In the review carried out, the need to introduce an integral geriatric assessment as a basic element in the care of the elderly was corroborated. Health centers that want to be age-friendly must incorporate these techniques in a systematic way, exploring the cognitive and emotional state, the functional capacity, the socioeconomic ${ }^{14}$ environment and the physical sphere. Within the latter, it is worth highlighting the control of the two most relevant chronic diseases: hypertension and diabetes. The organization of an age-friendly primary care center should be based on the horizontality of care, as well as on the coordination of social and health services. The administrations involved must be coordinated, since there are some areas of interaction between different agencies: transport systems, social and economic policies, health services, etc. In the literature observed, it is appreciated that these interactions are more relevant in health outcomes than the exclusive approach to physical barriers. ${ }^{15}$
The Figure 1 of the "care coordinator" of the patient should preferably be located in a primary care setting. Its functions include the rationalization in the number of medical visits, the coordination between primary and hospital care and the adequacy of information to the patient, including appointment reminder systems. Confidentiality and ethical aspects must prevail in all care. ${ }^{16}$ Community activities and the organization of community support networks that include knowledge of all available resources for the elderly in the area in which they live are two of the most relevant pillars to humanize care for the elderly care. One of the fundamental objectives is to achieve the empowerment of the elderly, increasing their knowledge and autonomy in decision making. As for the architectural barriers and the physical environment in of the health centers, the actions must be governed by the equitable use of resources regardless of the limitations of each patient. Flexibility, intuition and simplicity should direct the physical and organizational structures of the center. ${ }^{17}$ Displacements should require little physical effort, and there should be technical aids for the people who need them. Signage of the center must be adapted, as well as corridors, consultations, and waiting rooms and any other room. Attitudes of active listening, respect and empathy should be encouraged, understanding that it is easier for the elderly to make mistakes. The organization of the center must promote mechanisms to mitigate the effect of these errors, and ensure a dignified and quality treatment. ${ }^{18}$

\section{Conclusion}

The effects of health centers adaptation to generate age-friendly spaces on elderly's health has not been subject to relevant research on. This adaptation must revolve around several axes: physical barriers, clinical assistance, information to the patient, prevention and health promotion and social and community activities. The latter seem to be the most effective in terms of positive impact on the health of the individual.

\section{Acknowledgements}

None.

\section{Conflict of interest}

The author declares there is no conflict of interest.

\section{References}

1. United Nations. World Population Ageing 2013. New York (NY): United Nations; 2013. p. 1-114.

2. Worl Health Organization. Global essay on popultion ageing Android Heath. 2015.

3. Starfield B. Point: The Changing Nature of Disease. Implications for Health Services. Medical Care. 2011;49(11):971-972.

4. World Health Organization. Global cities friendly to the elderly: a guide. 2007.

5. Di Gessa G, Grundy E. The relationship between active ageing and health using longitudinal data from Denmark, France, Italy and England. $J$ Epidemiol Community Health. 2014;68(3):261-267.

6. Hawkesworth S, Silverwood RJ, Armstrong B, et al. Investigating associations between the built environment and physical activity among olderpeople in 20 UK towns. J Epidemiol Community Health. 2018;72(2):121-131. 
7. Alhamdan AA, Alshammari SA, Al-Amoud MM, Hameed, et al. Evaluation of health care services provided for older adults in primary health care centers and its internal environment. A step towards agefriendly health centers. Saudi Med J. 2015;36(9):1091-1096.

8. Matthews SA. The salience of neighborhood: some lessons from sociology. Am J Prev Med. 2008;34(3):257-259.

9. Wang D, Lau KK, Yu R, et al. Neighbouring green space and mortality in community-dwelling elderly Hong Kong Chinese: a cohort study. BMJ Open. 2017;7(7):e015794.

10. Neville S, Napier S, Adams J, et al. An integrative review of the factors related to building age-friendly rural communities. J Clin Nurs. 2016;25(17-18):2402-2412.

11. Woo J, Mak B, Yeung F. Age-friendly primary health care: an assessment of current service provision for older adults in Hong Kong. Health Serv Insights. 2013;6:69-77.

12. Petersen PE, Kandelman D, Arpin S, Ogawa H. Global oral health of older people--call for public health action. Community Dent Health. 2010;27(4 Suppl 2):257-267.
13. WHO Guidelines Approved by the Guidelines Review Committee. AgeFriendly PHC Centres Toolkit. World Health Organization; 2008.

14. De Hoyos Alonso MC, Gorroñogoitia Iturbe A, Martín Lesende I, et al. Actividades preventivas en los mayores. Actualización PAPPS 2018. Aten Primaria. 2018;50(Supl 1):109-124.

15. Greenfield EA, Oberlink M, Scharlach AE, Neal MB, Stafford PB. Agefriendly community initiatives: conceptual issues and key questions. Gerontologist. 2015;55(2):191-198.

16. van Hees S, Horstman K, Jansen $\mathrm{M}$, et al. Conflicting notions of citizenship in old age: An analysis of an activation practice. J Aging Stud. 2015;35:178-189.

17. Foy PJ. How do I ethically handle a request for confidentiality by an elderly patient? J Am Dent Assoc. 2010;141(4):463-464.

18. Rush KL, Hickey S, Epp S, et al. Nurses' attitudes towards older people care: An integrative review. J Clin Nurs. 2017;26(24):4105-4116. 